\title{
Investigating Multiple Devices Used in the Hotel Reservation Process
}

\author{
Chieh-Heng Ko \\ Department of Hospitality Management, College of Tourism and Hospitality, Da-Yeh University, Taiwan \\ Email: chko@mail.dyu.edu.tw
}

How to cite this paper: Ko, C.-H. (2018) Investigating Multiple Devices Used in the Hotel Reservation Process. Open Access Library Journal, 5: e4811.

https://doi.org/10.4236/oalib.1104811

Received: July 30, 2018

Accepted: August 24, 2018

Published: August 27, 2018

Copyright (c) 2018 by author and Open Access Library Inc.

This work is licensed under the Creative Commons Attribution International License (CC BY 4.0).

http://creativecommons.org/licenses/by/4.0/

\begin{abstract}
With the growing ownership of multiple technology devices, and the contribution of mobile travel bookings to the overall travel market, it is critical to investigate the hotel searching and booking process for different device users. This research investigates four categories of device users via a survey with 383 respondents, in the context of search behaviour and information sources used. The results reveal that search engines and family and friends are the most frequently used information sources while the personal computer (PC) is the most used device for both searching and booking. However, there is a significant difference in how these device users engage with information sources, specifically online travel agents (OTAs) and search engines. Furthermore, device users favor one device and are unlikely to switch devices during the search process.
\end{abstract}

\section{Subject Areas}

Public Health

\section{Keywords}

Hotel Reservation, Smartphone, Multi Devices, Channel Management

\section{Introduction}

With the increasing ownership of multiple devices, and the expansion of smartphone and tablet ownership among the travel population, the assumption that on-line travel planning was performed on a personal computer or laptop may no longer be justified [1]. More recently, Google and Ipsos MediaCT [2] reported travel planning was increasingly performed on multiple screens, and activities started on one device could be transferred, repeated or completed on another screen. 
The proliferation of smartphones and tablets now extends when and where customers engage with content. Heggestuen [3] stated that $22 \%$ of the global population now own smartphones, $20 \%$ own PCs (desktops and laptops), and $6 \%$ own tablets. Consumers select the combination of devices that best meets their needs and wants and increasingly smartphones are the device of choice for consumers, while tablets are gradually replacing traditional PCs.

Meanwhile, there has been a dramatic increase in information and booking channels available for customers [4]. Hotel customers use an extensive range of information through various channels such as search engines, comparison websites, supplier sites, and online travel agents (OTAs). An OTA, such as Expedia.com or Booking.com specializes in offering planning sources and booking capabilities from suppliers such as airlines, hotels and cruise companies who may also have their own sites, referred to as supplier sites [5]. Though research has been conducted on these channels and has clearly identified the most used information sources, they tended to focus specifically on travelers and destinations [6], and there is little investigation of the specific hotel booking context that often entails a lengthy, complex booking process [7]. Google and Ipsos MediaCT [2] also reported that travelers planned journeys in micro-increments and switched between devices during the booking process.

Given the accelerating adoption of smartphones and tablets, the growing ownership of multiple devices, the contribution of mobile travel bookings to the overall travel market, and the reported different behaviors between smartphone and tablet users, it is imperative to investigate the hotel booking process for different device users. By examining the devices and information channels, this study will contribute not only to the literature but also to practice. The main contribution to the literature will be in examining the booking process and information channel behaviors for various device users. Despite the growing importance of multiple device use, there has been limited, academic or empirical research, especially at the critical stages of information search and booking. Related studies examined some aspects of device usage in travel but failed to investigate the synergies between various devices and emerging information channels. Thus, this research aims to fill the gap and investigate the range of multi-use devices with the information sources and booking processes used. It contributes to our understanding of the information search behavior for a range of device users, not just the solitary examination of mobile use. Thus it includes PC users, smartphone users, tablet users, and traditional landline phone users. This research will also contribute to managerial practice in a number of ways, for example, to inform the design of content for specific devices and promote responsive websites for consumers. It further answers a call by previous researchers [8] that further research on devices "should extend beyond the focus on functionalities... the dialectic worldview suggests that the opposite side of the phenomenon (i.e. the non-use of smartphones) is also critical for a comprehensive understanding of the phenomenon" (p. 25). 
Eriksson [9] identify and categorize segments of mobile users by ownership, frequency or usage. However, in our research we use the device/s to categorize users in order to give a wider perspective of all commonly used devices and ensure that mobile and fixed devices are therefore included as information search still depends on both online and offline modes. Fesenmaier, Xiang, Pan, and Law [10] have identified the five most frequently used information sources, search engines, OTAs, suppliers' sites, review sites, and friends and family and these channels will be examined here. The over-arching research question is, Are there significant differences in the use of devices in information searching and in the hotel booking process? In particular, three sub-questions will be addressed in this study:

1) Do device users use information sources differently?

2) When we compare PC users against other device users, do they use information sources differently?

3) When comparing PC users against other device users, do they use these devices differently?

\section{Literature Review}

\subsection{Information Sources and Multiple Devices}

Information sources are composed of internal and external sources [11]. Internal sources are dependent on personal experiences and knowledge and external sources tend to be commercially based and market-dominated. The Internet is now the most important external source of information for travel planning and hotel booking [10]. Customers search and consult information sources prior to booking accommodation more frequently than other travel related products [6]. Fesenmaier et al. [10] rank travel-related websites in the following order in terms of sources of information, that is, general search engines, suppliers' sites, OTAs, friends and family, review sites, destination sites, general travel sites, travel search engines, travel guidebook sites, community sites, newspaper/magazine sites, consumer content generates sites, and social networking sites. Verma, Stock, and McCarthy [12] state that travellers use different websites during different stages, with search engines more important at the beginning of information search, while review sites, suppliers' and OTA sites are essential during the comparing and considering stage. Suppliers and OTA sites are more important at the booking stage. Anderson [13] reports that, among suppliers' site bookers, $75 \%$ have previously visited OTAs and $83 \%$ visited search engine sites before booking. Google dominates the search engine market with $92.8 \%$ of the European market [14]. Though the search engines are not information sources as such, they are tools for finding information and thus play a mediating role for consumers in the search process.

\subsection{Multiple Devices and Booking}

These multiple devices are characterized by certain features and functions. The 
PC (desktop and laptop) is less portable but has a physical keyboard and more storage capacity. It is supported by a range of business software that is compatible with certain accepted protocols and standards. The tablet format is specifically designed for graphic display and ease of reading, though the virtual keyboard uses up half the display, resulting in less functionality when typing. The smartphone is portable, versatile and accessible virtually anywhere. A smartphone combines cellular phone, Internet access, e-mail, music and movie player, camera and camcorder, GPS navigation system and several built-in applications, with versions for iPhone, Android, BlackBerry and Windows Phone [2]. Smartphones and tablets are used more for leisure purposes and PCs (desktop and laptops) are more task or work based. The traditional landline phone has limited capacity to transmit and store voice messages whereas laptops, tablets, and smartphones are computing devices with distinct benefits and disadvantages.

Hotel booking behavior patterns also vary widely between devices and activities. Google and Ipsos Media CT [2] report that, during the online research process, $88 \%$ of travel search is performed on PCs/tablet, compared to $27 \%$ smartphone. Hotel bookings are mostly completed on PCs/tablets (81\%) in preference to smartphones (21\%) with post purchase sharing divided between PCs/tablets (57\%) and smartphones (50\%). Furthermore, both tablets and smartphones have unique functions in the travel purchasing process [2]. Walsh [15] reports that even though tablet users also own smartphones, they tend to use tablets to select destinations, for shopping and booking. Google and Ipsos Media CT [2] reported smartphone sales tend to be smaller in value or simpler transactions, involving last-minute hotel stays or car rental, while tablet sales tend to be larger transactions involving longer trips.

\subsection{Mobile and Travel-Specific Technologies}

Increasingly, mobile technology adoption is characterized by the use of "smartphones" and "tablets". Smartphones and tablets support ubiquitous computing, contextual computing, pervasive computing, ubiquitous connectivity to the Internet, and integration of various sensors [16]. Smartphones have changed tourist behaviors, information needs, decision making, and experience documenting and sharing [16]. The portable nature of smartphones and tablets have prompted researchers to investigate both pre-trip and during trip traveler behaviors [9]. The perceived benefits of using mobile technology have been explored by several researchers [17] and include ubiquity, convenience, immediacy, personalization, information access, pragmatism, money savings, innovation, planning capacity, and entertainment. Similarly, investigation of the perceived barriers to use mobile technology during the trip have been widely examined and focus on high entry costs, usage costs, security issues, poor technology capability, and lack of relevant services [9].

Other researchers have addressed some behavioral characteristics and different contexts in the use of mobile technology devices. For example, Peres, Correia, and Moital [18] investigated intention to use and habitual use and MacKay 
and Vogt (2012) have explored specific contexts such as examining the "spillover" theory to explain the adoption of mobile technology devices from everyday life and use. Most researchers highlight the next wave of innovation will come from the accelerating growth of applications and the capacity of mobile technology [19]. Though these studies provide insights into device user behavior, they fail to examine specific device use for explicit tasks in the hotel booking process.

\subsection{Segmenting the Device Market}

Okazaki et al. [20] identified segments of mobile user as; savvies, planners, opportunists, and low-techs. These segments differ in their mobile usage patterns, and perceived benefits of mobile internet usage. Alternatively, MacKay and Vogt [21] used IT equipment ownership and frequency of Internet use to categorize respondents. Eriksson (2014) focused on activities conducted on mobile devices and identified five segments; allrounders, bookers, checkers, info-seekers, and non-users. PCs remain highly relevant to all travel activities, including search, reserve, pay, change/cancel, check-in, and reflect. Yet, smartphones and tablets are increasingly used for these activities, such as change/cancel, check-in [9]. Given the accelerating adoption of mobile devices, and the "spillover" effect of IT use, more research is needed in identifying behavioral aspects of multiple devices users, including mobile service users [9].

The hotel booking process has become even more complex, including multiple points of contact while consumers revert to a wide and diverse range of information sources on a variety of devices, which makes the context of hotels a unique phenomenon worthy of study. In our research, we use the device/s to segment the market and users in order to provide a specific investigation of the commonly used devices in the hotel booking process. Explicitly, Wang et al. [19] recommend future research should focus on the influence of mobile devices on travel planning. Furthermore, Lamsfus et al., [16] argued that the widely accepted and researched technology acceptance model (TAM) could be enhanced by considering the importance of incorporating the specificity of technology characteristics and usage contexts.

\section{Methodology}

The goal of this study is to identify the relationships between multiple device users, information searching and the final hotel booking. The research design is predominately quantitative in this investigation. The use of multiple devices in hotel booking and information searching is the context under examination and this goal can be examined best through a survey method [22]. Thus this study employed a survey instrument to investigate the range of devices used in the information searching and booking stages of the hotel room. The devices investigated in this study are PCs (laptop and desktop), smartphones, tablets, and traditional phones. The information sources, as identified by previous researchers are; search engines, OTAs, suppliers' sites, review sites, and friends and family. 


\subsection{Research Instrument}

Whittaker [8], Walsh [15] have variously identified the several devices and information sources used in the buying process. From this established research, we developed a three-part, structured questionnaire for this study. In the first part, the respondents were asked to refer to their most recent hotel reservation and identify the devices used to search and the device used to make the final booking. Respondents indicated their various use of devices in four close-ended, dichotomous format questions. For the device used in the final booking, respondents selected only one of the four devices. In the second part, respondents indicated which five information sources were used as sources in their pre-trip planning by responding to five close-ended, dichotomous format questions.

\subsection{Instrument Administration}

A convenience, purposive sample was drawn from within Switzerland as there are identifiable respondents that match the required profile. The data collection was conducted from October 2017 till January 2018 and administered by email. The sample frame included email contacts from our own institution and known multi-device users who had recently participated in the hotel booking process. After recruitment of this initial set of participants, a snowball technique was used where the initial seed respondents were asked to refer the survey by email to others who share the same multi-device use, and specifically to give a more diverse variety of respondents [23]. All instructions were included in the questionnaire. Snowball sampling is a non-probability sampling technique and used in hard to reach populations, such as multi-device users who are engaged in a specific activity, in this case booking a hotel room [24].

There were 403 returned questionnaires with 383 usable results. Based on our over-arching research question and three main research questions postulated, the data was analyzed using descriptive statistics, chi-square tests, and multinomial logit regression. The demographic data and frequencies are presented in percentages in tables. Chi-square is used to investigate the significant differences between device users and information sources. Multinomial logit regression allows the comparison between the reference group (the PC users) and other categories (tablet users, smartphone users, and phone users), individually. Multinomial logit regression is used to compare device users' information sources and to compare the multiple uses of devices. The results are presented in the tables below.

\section{Results}

Eriksson [9], MacKay and Vogt [21] and Okazaki et al. [20] used IT equipment ownership and frequency of Internet use to categorize respondents. Here, the device used to make the hotel booking is used to categorize respondents into four segments, specifically, PCs users, tablet users, smartphone users, and (traditional) phone users. 
As shown in Table 1, respondents use a wide range of channels as information sources for hotel pre-purchase decisions. Search engines were used by $64 \%$ of respondents, representing the information source with the highest usage. This is followed by family and friends (58\%), suppliers' sites (54\%), OTAs (45\%), and review sites (42\%).

Table 2 presents the usage of information sources by multiple device users. Each row is one of the five information sources. Each column represents a category of device users. For example, general search engines are used by $68 \%$ of PC users, $59 \%$ of tablet users, $48 \%$ of smartphone users, and $52 \%$ of phone users. Also, within the PC user group, $68 \%$ use general search engines, $58 \%$ use family and friends, 54\% use suppliers' sites, $49 \%$ OTA sites, and 44\% review sites.

Table 2 indicates different behaviors among device users. Smartphone users are most likely to consult family and friends as sources of information, as are the traditional phone users. Tablet users, by contrast, are most likely to consult OTAs and search engines compared to other sources. To confirm if these differences are statistically significant, chi-square tests have been conducted.

Table 3 shows the results from the chi-square tests. It is evident that from the information source perspective, that there is a significant difference between device users in their use of general search engines and OTAs.

Table 1. Information sources used.

\begin{tabular}{cc}
\hline Information sources & All \\
\hline General search engine & $64 \%$ \\
Family and friends & $58 \%$ \\
Suppliers' sites & $54 \%$ \\
OTAs & $45 \%$ \\
Review sites & $42 \%$ \\
\hline
\end{tabular}

Table 2. Information sources by category of device users.

\begin{tabular}{ccccc}
\hline Information sources & PC users & Tablet users & Smartphone users & Phone users \\
\hline General search engines & $68 \%$ & $59 \%$ & $48 \%$ & $52 \%$ \\
Family and friends & $58 \%$ & $45 \%$ & $64 \%$ & $62 \%$ \\
Suppliers' sites & $54 \%$ & $41 \%$ & $52 \%$ & $58 \%$ \\
OTAs & $49 \%$ & $59 \%$ & $20 \%$ & $25 \%$ \\
Review sites & $44 \%$ & $45 \%$ & $28 \%$ & $33 \%$ \\
\hline
\end{tabular}

Table 3. Chi-square test results e comparing device users' information sources.

\begin{tabular}{cc}
\hline Information sources & Chi square value $^{\mathrm{a}}$ \\
\hline General search engine & $7.85^{\star * *}$ \\
Family and friends & 2.06 (n.s.) \\
Suppliers' sites & 1.83 (n.s.) \\
OTAs & $18.76^{* * *}$ \\
Review sites & 4.68 (n.s.) \\
\hline
\end{tabular}

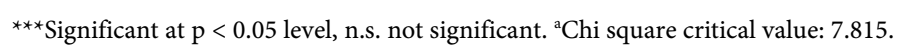


Multinomial logit regression was applied to investigate the differences in the use of information sources. The first multinomial logit regression compares three categories of device users (tablet, smartphone, and phone) with PC users, in terms of how they use information sources. As presented in Table 4, the coefficients for the intercept and OTAs are significant. Negative coefficients can be interpreted as less likely to occur, while positive coefficients are more likely. Specifically, compared to PC users, smartphone and traditional phone users are less likely to use OTA sites.

Table 5 presents the usage of devices by device users during the search process. Each row is one of the four devices. Each column represents a group of device users. For example, the PC is used by $98 \%$ of PC users, $73 \%$ of tablet users, $64 \%$ of smartphone users, and $71 \%$ of phone users. Also, of the PC user group, $98 \%$ use PCs, $23 \%$ use tablet, $25 \%$ use smartphones, and $22 \%$ use phones. This table indicates that PC users are comparatively low users of other devices, while other users tend to employ several devices.

To test different behaviors among device users, we conducted a multinomial logit regression. The second multinomial logit regression compared the three groups of device users with PC users on their use of different devices in the search process. The results from the second multinomial logit regression are presented in Table 6 . This table indicates that customers have a preferred device

Table 4. Multinomial logit results e comparing device users' information sources.

\begin{tabular}{ccccccc}
\hline Group & Intercept & $\begin{array}{c}\text { Search } \\
\text { engine }\end{array}$ & $\begin{array}{c}\text { Family and } \\
\text { friends }\end{array}$ & $\begin{array}{c}\text { Supplier } \\
\text { sites }\end{array}$ & $\begin{array}{c}\text { OTA } \\
\text { sites }\end{array}$ & $\begin{array}{c}\text { Review } \\
\text { sites }\end{array}$ \\
\hline Tablet/PC & $2.1148^{* * *}$ & $0.4884^{*}$ & $0.4538^{*}$ & 0.3517 (n.s.) & $0.4337^{*}$ & 0.0961 (n.s.) \\
Smartphone/PC & $1.7645^{* * *}$ & 0.3923 (n.s.) & 0.1900 (n.s.) & 0.1339 (n.s.) & $1.1898^{* * *}$ & 0.2035 (n.s.) \\
Phone/PC & $1.2049^{* * *}$ & $0.3819^{*}$ & 0.0907 (n.s.) & 0.1111 (n.s.) & $0.9131^{* * *}$ & 0.0923 (n.s.) \\
\hline
\end{tabular}

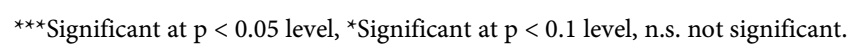

Table 5. Device used in the search process by device users.

\begin{tabular}{ccccc}
\hline Device & PC users & Tablet users & Smartphone users & Phone users \\
\hline PC & $98 \%$ & $73 \%$ & $64 \%$ & $71 \%$ \\
Tablet & $23 \%$ & $64 \%$ & $16 \%$ & $21 \%$ \\
Smartphone & $25 \%$ & $41 \%$ & $60 \%$ & $12 \%$ \\
Phone & $22 \%$ & $9 \%$ & $28 \%$ & $60 \%$ \\
\hline
\end{tabular}

Table 6. Multinomial logit results e comparing the use of devices.

\begin{tabular}{cccccc}
\hline Group & Intercept & PC & Tablet & Smartphone & Phone \\
\hline Tablet/PC & $0.8648^{\star * *}$ & $2.5711^{\star * *}$ & $1.7198^{\star * *}$ & 0.2730 (n.s.) & $1.3398^{\star * *}$ \\
Smartphone/PC & 0.5090 (n.s.) & $2.7654^{\star * *}$ & $0.7262^{*}$ & $1.2325^{\star * *}$ & $0.5077^{\star}$ \\
Phone/PC & $0.5610^{*}$ & $3.0523^{\star * *}$ & 0.1776 (n.s.) & $1.4272^{\star * *}$ & $1.9684^{\star * *}$ \\
\hline
\end{tabular}

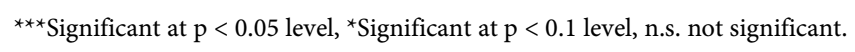


to search. Tablet users prefer their tablets to search while smart-phone and phone users remaining loyal to their phones. It also shows that compared to PC users, all three other groups of users are less likely to use PCs to search, and more likely to use their preferred devices to search. Furthermore, compared to PC users, tablet users are less likely to use their phones, while traditional phone users are less likely to use smartphones. Additionally, the smartphone users are less likely to use tablets and more likely to use phones, though these findings are only significant at 0.1 level.

\section{Discussion and Implications}

This paper investigates the range of devices used in the hotel booking process, the information sources used by device users and compares behaviors among device users.

As shown in Table 2, although PCs remain the most used device in the search process, tablets, smartphones and phones also are used by about one-quarter of respondents. This confirms that when searching for hotel accommodation, travelers do adopt a multi-device approach. Nonetheless, PCs remain highly relevant in the search process, as reported by Eriksson [9] and Google and Ipsos MediaCT [2]. Respondents return to their PCs (74\%) and traditional phones to make the final hotel booking. In this study, $13 \%$ of travellers used phones to book hotel rooms, similar to results reported by Schegg et al. [25]. These findings confirm the importance of accessible content through multiple devices, as well as having the appropriate staff to respond to phone enquires and bookings.

In terms of information sources used in the hotel booking context, the importance of search engines, friends and family, supplier sites, OTAs, and review sites are comparable to results from other researchers [2] [11]. It is noteworthy that friends and family remain a major influence and this traditional information source is still a key part of the booking decision. This finding supports research by Kim, Lehto, and Morrison [17] [26].

The dominance of search engines is highlighted here, as travelers consult search engines on a regular basis in their daily lives, and extend their use of search engines to conduct their hotel accommodation search, referred to as the "spillover effect" [19] [21]. The introduction of Google HotelFinder and Google Carousel may also promote the use of Google as a more detailed source of information to inform hotel bookings. OTA sites are also being extensively used as information sources. The variety of hotel selections, comparability, user-friendliness of the site and mobile-friendly content offered by OTAs may contribute to their popularity.

Table 5 shows that various device users use search engines and OTA sites differently. In Table 6, the multinomial logit results further indicate that compared to PC users, smartphone and phone users are less likely to use OTA sites. To a certain extent, compared to PC users, both tablet and phone users are less likely to use search engines. These findings indicate that investing resources to im- 
prove search engine results and OTA ranking results may satisfy only PC users, but may prove somewhat redundant for the other device users.

Table 5 and Table 6 clearly demonstrate that, for devices used in the search process, users have their preferred devices, and they are significantly less likely to use other devices. In comparison to PC users, all other device users are less likely to use PCs. This finding confirms that the assumption that all web interactions are mainly taking place between users on PCs is no longer valid [15]. Furthermore, these findings also confirm tablet and smartphone users have different behaviors [2]. Tablets and smartphones have smaller screens, can present fewer results per screen, and are more challenging for users to input data. Despite these constraints, tablet and smartphone users still prefer to conduct their hotel search on these devices.

Hotel managers need deep insights into the devices that their customers are most likely to use, ensuring relevant content is available on those devices, thus giving a consistent online experience. This study highlights that customers have different device preferences in both the search process and booking, and these preferences must be accommodated when deploying digital marketing strategies to increase visibility and bookings. It is crucial that hoteliers do not assume that PC/laptop users are their typical customers and thus design content and website information architecture based solely on desktop use. Although most reservations may come from PCs, customers tend to search on several different devices before the final booking and thus tracking users across multiple devices would provide more accurate information about the customer journey. It would also provide a seamless experience for the customer; though tracking across a variety of browsers, applications and networks remains a challenge. Whatever the device used, hotel websites and preferred channels must be "responsive", that is, able to detect the device in use and convert the website experience to the functionalities of the device. As smartphone and phone users are less likely to use OTA sites, this presents problems for hotels that have relied on OTAs and the "billboard effect" (Anderson, 2011) to generate visibility. Hotels need to be present on the channels where smartphone users are more likely to be "looking" and "comparing" before "booking". Hoteliers should also be aware of the specific barriers preventing customers from booking through smartphones and tablets.

Though mobile bookings are still relatively low compared to other channels, smartphone and tablets are used increasingly to share information. Google and Ipsos MediaCT [2] reported that customers demand download speed, design customized to device, and compatibility from mobile devices. Hoteliers need to ensure that their content and web presence 'fits' the screen size(s) of these devices to enhance the usability at any stage during the booking process. Furthermore, they must provide customized content that communicates the hotel's value proposition on mobile channels/devices/partners, particularly at the information searching stage. Given the increasing switching behavior [2], this content must be consistent across all channels and devices, to retain customers and minimize confusion. This will require vigilance and investment in content and 
channel management from hotel marketers.

Search engines are the most important information sources, despite not being the content owners. This magnifies the importance of search engine optimization (SEO) of the hotel's website. Search engine result pages (SERPS) are further limited in size on tablets or mobile phones. As customers become more mobile, SEO on smaller screens will present increasing challenges of visibility, already a problem for individual hotels where the big players like Booking.com and Tripadvisor, dominate search engine results. As hotel search is dominated by Google [2], this creates further obstacles for hotel marketers, as Google changes its algorithm and limits the search result presentation by including paid hotel links on the first SERP, along with a Google map marking the hotel locations. In addition, Google has developed Google Hotel Finder and Google Carousel, which further intensifies the competition for visibility. Hoteliers should manage their Google Business accounts to improve their visibility on search engines, Google Hotel Finder, Google Carousel, and Google Maps. In addition, hotels need to work with either OTAs or customer reservation systems (CRSs) to deliver real-time rates and availabilities on Google Hotel Finder.

Though a simple proposition, hotel marketers must remain aware that most information sources serve a dual purpose, providing information but also serving as booking channels [27]. It is therefore important to track the consumption path and map key customer touch points in order to determine which channels are critical and convert information seekers to hotel bookers. This means that hotels must invest in more sophisticated customer tracking by using 'cookies' or agencies that will gather this critical information and inform channel investment. As customers migrate and switch to different channels and devices, it is critical to remain in their consideration set at the information seeking stage.

\section{Conclusions}

This research contributes to the existing literature by linking the devices used in the hotel search process with information sources and channels. Device users have their preferred devices and are less likely to use other devices. Furthermore, there is a significant difference in the way device users use OTAs and search engines. The results indicate that hoteliers should implement a multi-channel distribution management system across devices, taking into account different devices and the information criteria and formats that could be used to reach customers.

Our results confirm that market-dominated sources, which are the search engines and OTAs, have a dominant position in the marketing of hotels. Hotel marketers need to effectively manage both easily managed channels, such as their own site, and more complex channels, such as OTAs and review sites. Given that friends and family continue to be an important source of information for hotel bookings, it remains critical to have effective customer relationship management incentives for guests to promote the hotel in a positive manner. 
Hotel marketers should provide accurate and appealing information, across different channels, to facilitate customers' decision making. In addition, hoteliers should leverage their brand sites to have direct contact with potential customers.

There were several limitations of this study. First, a convenience, Swiss-based, partly student sample, makes generalization to a wider population limited and the bias inherent in the sampling approach prevents inference to the general population. Secondly, the survey was based upon a recalled hotel booking, which differs from an actual hotel booking, where there is greater risk involved and more scrutiny given to booking requirements and pre-requisites. Nonetheless, it provides an insight into the changing role of channels and the multiple uses of devices for hotel room bookings.

Future research should explore the customer's level of attachment to their preferred devices and the specific nature of the "spillover effect" from everyday life to travel and particularly hotel bookings [19] [21]. Further research is also needed to investigate and explain why different device users have different preferences in the use for their devices, and use search engines differently. Though Eriksson [9] identified barriers to use mobile technology during trips, this does not explain the lack of mobile hotel bookings, with the exception of "same day" reservations. Investigation to identify these specific barriers to mobile bookings would provide insights for all information providers and booking channel operators. OTAs are more advanced in developing applications (apps), yet smartphone users in this study prefer other sources than OTAs and their apps. This is critical information for hotel marketers who must decide where to invest their marketing budget, develop apps and invest in smartphone friendly platforms and strategic partners.

In addition, this research focuses on hotel bookers' search behavior. Future research should investigate hoteliers' actual channel management practices and identify if alignment exists between hotel booking behavior and hoteliers' channel management. Lastly, previous researchers argue that Technology Acceptance Model is limited in explaining technology adoption behavior, and advocate research that could focus on monitoring the actual behavior [16], and investigate the barriers to use and carefully consider other ways to segment users [9]. This research partially addresses these issues as we investigate device users and differentiate information sources from the booking process.

\section{Conflicts of Interest}

The authors declare no conflicts of interest regarding the publication of this paper.

\section{References}

[1] Walsh, C.S. (2017) Mobile to Represent over One Quarter of U.S. Online Travel Market by 2018.

http://www.phocuswright.com/research_updates/mobile-to-represent-over-one-qua rter-of-us-online -travel-market-by-2018 
[2] Google and Ipsos MediaCT (2014) The 2014 Traveler's Road to Decision. https://www.thinkwithgoogle.com/consumer-insights/2014-travelers-road-to-decisi on/

[3] Heggestuen, J. (2013) One in Every 5 People in the World Own a Smartphone, One in Every 17 Own a Tablet. Business Insider.

https://www.businessinsider.com.au/smartphone-and-tablet-penetration-2013-10

[4] Murphy, H. and Chen, M.M. (2014) Online Information Sources Used in Hotel Bookings: Examining Relevance and Recall. Journal of Travel Research, 55, 523-536. https://doi.org/10.1177/0047287514559033

[5] Benckendorff, P.J., Sheldon, P.J. and Fesenmaier, D.R. (2014) Social Media and Tourism. In: Tourism Information Technology, 2nd Edition, 120-147. https://doi.org/10.1079/9781780641850.0120

[6] Jun, S.H. and Vogt, C.A. (2013) Travel Information Processing Applying a Dual-Process Model. Annals of Tourism Research, 40, 191-212. https://doi.org/10.1016/j.annals.2012.09.001

[7] Filieri, R. and McLeay, F. (2014) E-WOM and Accommodation an Analysis of the Factors That Influence Travelers' Adoption of Information from Online Reviews. Journal of Travel Research, 53, 44-57. https://doi.org/10.1177/0047287513481274

[8] Wang, D., Xiang, Z. and Fesenmaier, D.R. (2014) Adapting to the Mobile World: A Model of Smartphone Use. Annals of Tourism Research, 48, 11-26. https://doi.org/10.1016/j.annals.2014.04.008

[9] Eriksson, N. (2014) User Categories of Mobile Travel Services. Journal of Hospitality and Tourism Technology, 5, 17-30. https://doi.org/10.1108/JHTT-10-2012-0028

[10] Fesenmaier, D.R., Xiang, Z., Pan, B. and Law, R. (2011) A Framework of Search Engine Use for Travel Planning. Journal of Travel Research, 50, 587-601. https://doi.org/10.1177/0047287510385466

[11] Jacobsen, J.K.S. and Munar, A.M. (2012) Tourist Information Search and Destination Choice in a Digital Age. Tourism Management Perspectives, 1, 39-47. https://doi.org/10.1016/j.tmp.2011.12.005

[12] Verma, R., Stock, D. and McCarthy, L (2012) Customer Preferences for Online, Social Media, and Mobile Innovations in the Hospitality Industry. Cornell Hospitality Quarterly, 53, 183-186. https://doi.org/10.1177/1938965512445161

[13] Anderson, C.K. (2011) Search, OTAs, and Online Booking: An Expanded Analysis of the Billboard Effect. Cornell Hospitality Report, 11, 4-10.

[14] Rosoff, M. (2014) Here's How Dominant Google Is in Europe. https://www.businessinsider.com/heres-how-dominant-google-is-in-europe-2014-11

[15] Walsh, C.S. (2016) Mobile Travel Strategy Shakeup Ahead as Tablet Adoption Nears 50\%.

http://www.phocuswright.com/research_updates/mobile-travel-strategy-shakeup-a head-as-tablet-adoption-nears-50s

[16] Lamsfus, C., Wang, D., Alzua-Sorzabal, A. and Xiang, Z. (2014) Going Mobile Defining Context for On-the-Go Travelers. Journal of Travel Research, 54, 691-701.

[17] Kim, D.Y., Park, J. and Morrison, A.M. (2008) A Model of Traveller Acceptance of Mobile Technology. International Journal of Tourism Research, 10, 393-407. https://doi.org/10.1002/jtr.669

[18] Peres, R., Correia, A. and Moital, M. (2011) The Indicators of Intention to Adopt Mobile Electronic Tourist Guides. Journal of Hospitality and Tourism Technology, 2, 120-138. https://doi.org/10.1108/17579881111154236 
[19] Wang, D., Park, S. and Fesenmaier, D.R. (2012) The Role of Smartphones in Mediating the Touristic Experience. Journal of Travel Research, 51, 371-387. https://doi.org/10.1177/0047287511426341

[20] Okazaki, S., Campo, S., Andreu, L. and Romero, J. (2014) A Latent Class Analysis of Spanish Travelers' Mobile Internet Usage in Travel Planning and Execution. Cornell Hospitality Quarterly, 56, 191-201.

[21] MacKay, K. and Vogt, C. (2012) Information Technology in Everyday and Vacation Contexts. Annals of Tourism Research, 39, 1380-1401. https://doi.org/10.1016/j.annals.2012.02.001

[22] Collis, J. and Hussey, R. (2009) Business Research: A Practical Guide for Undergraduate and Postgraduate Students. 3rd Edition, Palgrave Macmillan, Basingstoke.

[23] Chang, H.H. and Chen, S.W. (2008) The Impact of Online Store Environment Cues on Purchase Intention: Trust and Perceived Risk as a Mediator. Online Information Review, 32, 818-841. https://doi.org/10.1108/14684520810923953

[24] Gabor, M.R. (2007) Types of Non-Probabilistic Sampling Used in Marketing Research, Snowball Sampling. Management \& Marketing (Bucharest), 3, 80-90.

[25] Schegg, R., Stangl, B., Fux, M. and Inversini, A. (2013) Distribution Channels and Management in the Swiss Hotel Sector. Springer, Heidelberg Berlin, 554-565. https://doi.org/10.1007/978-3-642-36309-2_47

[26] Litvin, S.W., Goldsmith, R.E. and Pan, B. (2008) Electronic Word-of-Mouth in Hospitality and Tourism Management. Tourism Management, 29, 458-468. https://doi.org/10.1016/j.tourman.2007.05.011

[27] O'Connor, P. and Frew, A.J. (2002) The Future of Hotel Electronic Distribution: Expert and Industry Perspectives. The Cornell Hotel and Restaurant Administration Quarterly, 43, 33-45. https://doi.org/10.1016/S0010-8804(02)80016-7 